\title{
A TEORIA DA COMPLEXIDADE E O ECOSSISTEMA DO TURISMO
}

\author{
THEORY OF COMPLEXITY AND THE TOURISM ECOSYSTEM
}

\section{LA TEORÍA DE LA COMPEJIDAD Y EL ECOSISTEMA DEL TURISMO}

\author{
Mario Carlos Beni \\ Professor Titular Aposentado da Universidade de São Paulo (USP) \\ Professor Convidado do curso de Mestrado em Turismo da Universidade de Brasília (UnB) \\ Professor Convidado do curso de Mestrado em Turismo da \\ Universidade de Caxias do Sul (UCS) \\ Doutor em Ciências da Comunicação \\ Livre-docente em Turismo da ECA/USP \\ beni@usp.com
}

Marutscka Moesch Professora do Curso de Mestrado em Turismo-Universidade de Brasília (UnB) Doutora em Ciências da Comunicação ECA/USP marumoesch@gmail.com

RESUMO: O artigo ensaístico proposto discorre sobre domínio material e conceitual do turismo tendo como tese o objeto da ciência. Tem como objetivo analisar a fragilidade das teorias de indução empírica, e a atitude positivista, em que ocorre uma explícita subordinação do imaginário pela observação do fato. A nova síntese tem como método a transdisciplinaridade, atitude analítica da teorização enraizada, a partir da sociologia compreensiva e da Teoria da Complexidade de Edgar Morin, que leva a uma epistemologia derivada, cuja relação de sujeito/objeto reconstrói-se organicamente e de forma complexa, estabelecendo-se o domínio da psicogênese e da sociogênese do conhecimento turístico, recuperando os valores humanos no discurso científico do Turismo pela Teoria da Complexidade. O resultado deste novo olhar epistemológico é a proposição de um modelo ecossistêmico do turismo.

PALAVRAS-CHAVE: Epistemologia do turismo. Teoria da Complexidade. Modelo Ecossistêmico do turismo.

ABSTRACT: This essay addresses the material and conceptual field of Tourism, having as its thesis the object of science. Its objective is to analyze the fragility of theories of empirical induction, and the positivist attitude, where an explicit subordination of the imaginary occurs through the observation of fact. A method of the new synthesis is transdisciplinarity, an analytical attitude of rooted theorization, based on comprehensive sociology and Edgar Morin's Complexity Theory, which leads to a derived epistemology in which the relation of subject/object is reconstructed in an organic and complex way, establishing the field of psychogenesis and sociogenesis of tourist knowledge, and recovering the human values in the scientific discourse of Tourism through the Theory of Complexity. The result of this new epistemological perspective is the proposition of an ecosystemic model of Tourism.

KEYWORDS: Tourism Epistemology. Theory of Complexity. Ecosystem Model of Tourism.

RESUMEN: El artículo propuesto, que es un ensayo, discurre sobre el dominio material y conceptual del Turismo, y su tesis es el objeto de la ciencia. Su objetivo es analizar la fragilidad de las teorías de inducción empírica y la actitud positivista, en la que ocurre una explícita subordinación de lo imaginario por la observación del hecho. La nueva síntesis tiene como método la transdisciplinaridad, actitud analítica de la teorización enraizada, a partir de la sociología comprensiva y de la Teoría de la Complejidad de Edgar Morin, que lleva a una epistemología derivada, cuya relación de sujeto/objeto se reconstruye orgánicamente y de forma compleja, estableciéndose el dominio de la psicogénesis y 
PALABRAS CLAVE: Epistemología del Turismo. Teoría de la Complejidad. Modelo Ecosistémico del Turismo.

\section{INTRODUÇÃO}

reflexão epistemológica impõe aos próprios pesquisadores os
instrumentos de conhecimento dos quais as ciências dispõem,
reflexão com vista a superar as crises revendo a pertinência dos conceitos, das teorias e dos métodos diante das problemáticas que são objeto de suas investigações, razão desse artigo. Esse processo de produzir ciência tem por princípio a universalidade, que deve conter cada conceito, pois sua validade não pode ser generalista e nem ocasional, mas sim produto do movimento da história, em que: [...] Em primeiro lugar, o ser em seu conjunto é visto como um processo histórico; em segundo, as categorias não são tidas como enunciados sobre algo que é ou que se torna, mas sim como formas moventes e movidas da própria matéria, para Luckás (1978), são formas do existir, determinações da existência.

Uma epistemologia do Turismo envolve cuidados teóricos, advindos de um entendimento complexo sobre uma prática social que se dissemina de formas diferenciadas, a partir de subjetividades infinitamente diversas e de vivências múltiplas dos sujeitos que as praticam, em territórios globalizados, o que é possível por uma visão interdisciplinar e hologramática.

O princípio hologramático, para Morin (2001), em sua obra Introdución Al Pensamiento Complexo, destaca o aparente paradoxo de certos sistemas em que não somente a parte está no todo, como também o todo está na parte: a totalidade do patrimônio genético está presente em cada célula individual. Da mesma forma, o indivíduo é uma parte da sociedade, mas a sociedade está presente em cada indivíduo como um todo, por intermédio de sua linguagem, sua cultura, suas normais.

A concepção interdisciplinar vem ao encontro como método investigativo. Impõe um exercício fecundo sob o ponto de vista epistemológico, não deixando 
de salientar sua demasiada ousadia, diante dos nichos particularistas existentes na academia, cujos clássicos campos do saber são criteriosamente delimitados. $O$ turismo é bem mais que estas conceituações reducionistas sob olhar disciplinar as quais o caracterizam como setor/atividade dos estudos de econometria.

Construir um novo campo teórico para o turismo requer um método que avance na concepção do que seria conhecimento, ciência e teoria. O tratamento disciplinar que vem sendo dado ao estudo do turismo tem dificultado em sua superação como setor econômico, que fez parte do contexto da produção do conhecimento científico na modernidade. Hoje, dentro dos desafios do mundo contemporâneo, urge desvelar as relações ecossociais dos sistemas complexos, relações cujos produtos e efeitos são necessários à sua própria regeneração, isto é , à sua própria existência, em que se constitui o campo social - anfitrião e turista - do turismo dos sistemas complexos em que se constitui o turismo.

Compreender a problemática do desenvolvimento crescente do turismo é relevante não só à medida que seus produtores, vendedores, intermediários e consumidores continuam produzindo, vendendo e consumindo sem limites ou critérios, sem outro fim que o próprio benefício do primeiro e a satisfação egoísta do consumidor, como pela persistência do problema, disfarçado nas concepções implícitas do seu conceito como negócio, que invade o tratamento das localidades e culturas, como demarcam as ações das políticas públicas.

Essa postura, de uma cultura de mercado capitalística, desconhece e desconsidera a essência do fenômeno turístico, que exerce uma pressão crescente sobre a produção da subjetividade social, o ecossistema, o modo estético, a herança cultural, existentes nas localidades, gerando agenciamentos possíveis de ressignificação junto à realidade, por meio da relação entre visitantes e visitados cada vez mais fugazes.

Turismo é processo humano, ultrapassa o entendimento como função de um sistema econômico. Como um processo singular, necessita de ressignificação às relações impositivas, aos códigos capitalísticos e aos valores colocados como patrimonialização cultural. Esse é objetivo de discussão do artigo proposto. A trilha metodológica percorre o paradigma da transdisciplinaridade, somada à atitude analítica da teorização enraizada, que leva a uma epistemologia 
derivada, cuja relação de sujeito/objeto reconstrói-se organicamente e de forma complexa, estabelecendo o domínio da psicogênese e da sociogênese do conhecimento turístico, recuperando os valores humanos no discurso científico do turismo pela Teoria da Complexidade.

Em um primeiro momento serão discutidas as bases epistemológicas, que vêm fundando os estudos do turismo, seguidas dos limites das teorias sistêmicas na construção de modelos explicativos enovas epistemes possíveis em sua concepção como campo de ciência, a partir da Teoria da Complexidade, compreendendo-a como um sistema complexo, expresso no modelo ecossistêmico.

\section{AS BASES EPISTEMOLÓGICAS DO TURISMO}

ACiêncianãoéumaleituradaexperiênciaa partirdoconcreto.Fundamentalmente, consiste em produzir, com a ajuda de abstrações e de conceitos, o objeto a ser conhecido. Ela constrói o seu objeto próprio pela destruição dos objetos da percepção comum. Seu progresso não se faz por acumulações, ou novas verdades vindas a justapor-se ou a sobrepor-se às já estabelecidas. O saber de turismo não é linear. Não há evolução, mas "revolução", progredindo por reformulações, por refusões em seu corpo teórico, por retificações de seus princípios básicos. É assim que ela marcha em direção a um saber sempre mais objetivável, jamais inteiramente objetivo. Até metade do séc. XX, a maioria das ciências tinha como método de conhecimento a especialização e a abstração, ou seja, a redução do conhecimento de um todo ao conhecimento das partes que o compõem (como se a organização de um todo não produzisse qualidades novas em relação às partes consideradas isoladamente). Sob a matriz de Bacon (1999), o conceito básico era o determinismo, em outras palavras, a ocultação da alteralidade, da novidade, e a aplicação da lógica mecânica, como uma máquina artificial aos problemas dos seres vivos da sociedade. Bacon (1999) afirma a plasticidade da natureza humana e, portanto, a sua perfectibilidade, dadas as condições sociais, jurídicas e políticas adequadas de determiná-las com rigor.

A tradição cartesiana, predominante no saber científico do turismo, fundamenta a análise na separação do todo em categorias, pressupondo que 
um campo de saber é suficiente para analisar e organizar as partes constituintes desse todo. A interdisciplinaridade e a transdisciplinaridade, aqui propostas como atitude científica, são fundamentais à análise do turismo como fenômeno social, cultural, comunicacional, econômico, possuidor de uma prática social e, por isso, também subjetivo, o que para seu entendimento coloca o pesquisador em uma posição de avanço sob as fronteiras de uma única disciplina ou de um único campo do saber.

As doutrinas que fundamentam a teoria a se elaborar determinarão o conteúdo e o método da mesma. Mas nessa construção há uma intencionalidade, a do sujeito (pesquisador), a do objeto como expressão da realidade à que pertence e da concepção de ciência (estrutura do conhecimento) que o apreenderá conforme o método utilizado. A Figura 1 demonstra as relações determinadas e determinantes do processo de construção do objeto turismo.

Figura 1: Relações epistemológicas

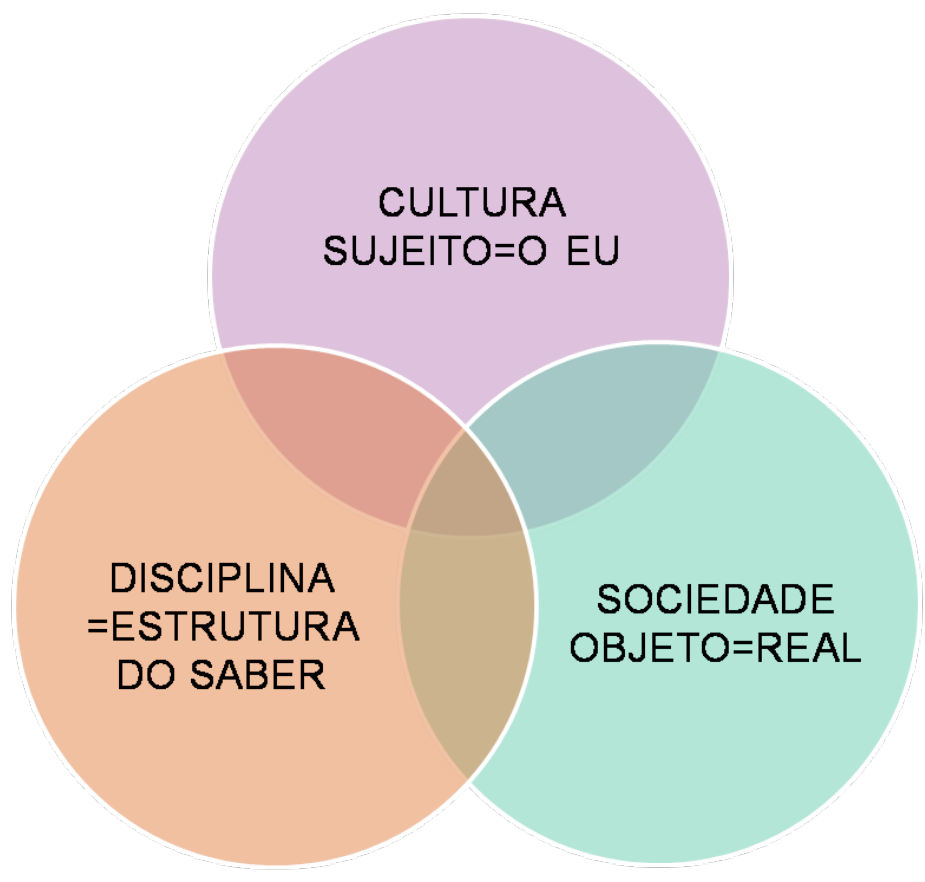

Fonte: Moesch (2012).

Os estudos de uma episteme do turismo demonstram que seu epicentro é de caráter humano, pois são os turistas que se deslocam e não as mercadorias. Isso implica, posteriormente, o esforço de uma argumentação sistemática desta realidade no que tange ao seu conhecimento. Basta que se pense na série importante de inter-relações sociais que derivam do comportamento "consumidorturista" com as comunidades dos destinos turísticos, e todo o complexo processo 
de identificação do turista com o grupo ideal (a exemplo da segmentação turística), ou efetivo, que determina a escolha da localidade de destino.

Dentro do campo paradigmático interdisciplinar, o modelo é uma construção metodológica que se operacionaliza em dois momentos: o da construção e reconstrução da estrutura do objeto, e o momento da construção e reconstrução do processo de conhecimento. Para construir uma ciência do turismo, deve-se ir muito além da construção de uma metodologia, já que esta não deve ter um fim em si mesmo, mas ser um meio para se atingir o fim cognitivo. $O$ que se deduz ser necessária, mas não ser suficiente, a construção de modelos explicativos, a exemplo dos modelos sistêmicos do turismo.

Compreendem-se paradigmas como constelações de crenças e valores e técnicas partilhadas por membros de uma comunidade científica, que se referem aos modelos, padrões compartilhados que permitem a explicação de certos aspectos da realidade e, por serem pertinentes a uma época, são biodegradáveis. Para estruturar novas teorias sobre o "que é o turismo", requer uma discussão lógica entre um conjunto de conceitos-mestres do campo do turismo que permearam suas explicações ao longo desses anos. O que seria uma discussão nuclear e ao mesmo tempo linguística, lógica e ideológica (Morin, 2001) sobre o paradigma de abordagem não fragmentada, racionalista, que reafirma uma visão do mundo em que há perfeita concordância entre as formas de explicação racional e a realidade do universo, excluindo, dessa forma, outras possibilidades de explicação, ou seja, "a verdade é que a ordem e a estabilidade do mundo são pré-condição da transformação tecnológica do real" (Santos, 2011, p.64). Paradigma instaurado sob o método hipotéticodedutivo que banha os estudos sobre o que é turismo.

A forma como os estudos sobre o turismo vem sendo propostos em diferentes territórios na contemporaneidade coloca a urgente questão sobre as teorias interpretativas que o formatam, pois traduz as concepções de conhecimento monodisciplinar, multidisciplinar, quiçá interdisciplinares, implícitas e subjacentes às propostas de seus modelos, ocasionando sérias implicações éticas, sociais, políticas, impactadas por suas práticas turísticas, pois é no bojo da complexidade dessas práticas e dos seus impactos às comunidades que esse artigo suscita reflexão. 


\section{A TEORIA SISTÊMICA NA CONSTRUÇÃO DA EPISTEMOLOGIA DO}

TURISMO

A Teoria Geral dos Sistemas, preconizada por Von Bertalanffy (1968), busca entender a parte a partir do todo, e aceita que o universo só é conhecido pelas relações entre suas partes, sempre em mudança, inter-relacionadas, organizadas em sistemas. Identifica propriedades estruturais que se manifestam em sistemas de diferentes campos científicos. Partindo do princípio de que as partes não podem ser conhecidas de forma isolada, mas sim dentro do sistema aberto a que pertencem, que as relações não são causais e unidirecionadas, mas circulares, e que o todo é diferente da soma entre as partes.

Já o método analítico consiste em dar uma modelo que mostre o real como construído, considerando-se seus elementos e base. Para encontrar um modelo adequado, os pesquisadores tentam determinar todos os componentes de um sistema para reconstruí-lo. Costuma-se opor esse método ao "método sistêmico", que se interessa menos pela reconstrução de um sistema de base em seus componentes, mas privilegia a compreensão do sistema como um todo. Segundo esse método, consideram-se como primordiais as interações entre os componentes, a ponto de considerar o sistema como uma caixa preta sobre a qual se vai avaliar o efeito dos diferentes inputs sobre os outputs.

O quadro sistêmico de análise reconhece numa problemática qualquer de pesquisa a predominância do todo sobre as partes e, por conseguinte, aborda seu objeto sob a forma coerente e globalizante de uma rede de relações. Tal quadro tende a prestar contas da totalidade das realidades sociais estudadas, privilegiando seus aspectos estruturais, querendo aprendê-los através do conjunto e das relações mútuas entre estes últimos. O todo social é visto como sistemas de indivíduos relacionados entre si.

Para o quadro interpretativo sistêmico, toda coisa é um sistema, ou um componente de algum sistema, cujo sistema é desde sua gênese um objeto complexo, em que as partes se mantêm unidas por vínculos de uma ou mais classes. Em particular, todas as características da sociedade, econômicas, 
culturais e políticas, formam uma peça única. Mesmo distintas, são inseparáveis. O sistemismo claramente engloba tanto o individualismo, pois tem em conta a composição, como a holismo, dado que enfatiza a estrutura da organização.

Os funcionalistas sistêmicos, a exemplo de Parsons, entendem que a sociedade forma um todo funcional, sistêmico; consequentemente, o turismo passa a ser um subsistema econômico dentro do mercado produtivo internacional. A mesma concepção metodológica é proposta por Leiper (1979), o qual propõe uma abordagem de sistemas ao estudo acadêmico do turismo por ter implicações potenciais em diversas áreas e em muitos níveis de análise. Para o autor, na pesquisa acadêmica o sistemismo pode servir como ponto de referência para estudos gerais e específicos, permitindo estudar sua estrutura e ênfase em conexões existentes entre e dentro de vários elementos do sistema, como: impactos comerciais, aplicações potenciais em diversas áreas da indústria turística, principalmente em empresas multissetoriais que operam em diversas locações. Pode ser particularmente útil para o planejamento do marketing, assim como um governo pode usar a estrutura para reconhecer relações de sua unidade eleitoral geográfica no sistema turístico completo Leiper (1979).

Lanquar (1984) aplica a teoria dos sistemas à gestão dos recursos humanos na organização turística, pois para ele é uma abordagem moderna que trata a empresa como um conjunto ou sistema de partes e subsistemas (estes subdivisíveis) e de variáveis mutuamente independentes, no qual a empresa turística é uma parte do sistema econômico e social, que pode ser considerada como um conjunto de organizações decorrentes e cooperantes, assim a empresa é o repartidor último dos recursos ou a célula última do sistema de inputs-outputs. Com frequência o sistemismo se confunde com o holismo, em particular com o conceito de sistemas de ação de Talcott Parson (1951). Sua versão holista e idealista do conceito de sistema, além de sua obscura teoria, produziu o descrédito da própria palavra sistema entre os estudiosos da sociedade.

Parsons (1951) coloca que a sociedade pode ser comparada a um sistema autor regulável. Sentencia um otimismo quanto à estabilização das economias em crescimento e o progresso social. Todas as crises, as revoluções, são vistas como rearranjos internos, tendo como horizonte a otimização do desempenho 
da sociedade. Para sua teoria, a sociedade é una, um todo consistente, um sistema, um conjunto de elementos ordenados pela razão, organizada por meio da imposição dos limites sobre as partes. Estes limites demarcam os campos do saber e do poder, como espaços sociais diferenciados, construindo uma visão reducionista e unidimensional da relação existente entre saber-poder. Tal visão impõe uma mutilação do real, na qual o outro é uma parte do todo uno e, portanto, traduzível em produto mercantilizável.

Sob o ângulo metodológico, um sistema comporta, pelo menos, segundo Bruyne (1977), a identificação dos elementos que o compõem (conjunto de unidades e objetos), a especificação das características ou das propriedades dos elementos, em relação às quais os estados dos sistemas podem ser descritos, a especificação das regras ou das leis que regem as interações dos elementos ou de suas propriedades, assim como a sucessão dos estados do sistema.

Os elementos constitutivos de um sistema podem ser qualquer coisa, desde que haja entre eles uma ordem, uma interdependência, um caráter relacional. A noção de sistema não remete a uma coisa, mas a uma ordem de coisas entre acontecimentos, fenômenos, variáveis. Por constituir um conjunto, o sistema implica que seus elementos tenham propriedades comuns em vez de únicas. A ordem que caracteriza o sistema concerne antes de tudo às relações entre as propriedades de seus elementos, suas qualidades ou seus estados, não entre unidades concretas como tais.

Um sistema ou complexidade organizada pode ser definido pela existência de fortes interações ou de interações não triviais, isto é, não lineares. Destas considerações decorre a necessidade de estudar não somente partes e processos isoladamente, mas também resolver os decisivos problemas encontrados na organização e na ordem que os unifica, resultante da interação dinâmica das partes, tornando o comportamento destas diferentes quando estudado isoladamente e quando tratado no todo.

O paradigma sistêmico, ao propor a ideia de que efeitos podem ser retroalimentadores de suas supostas causas dentro de um sistema e que observadores podem modificar pela via interativa o que estão a observar, criou um novo marco epistemológico, nos anos 1950, para referenciar os estudos, para 
pensar fenômenos tanto na Física quanto na Química, na Biologia e nas Ciências Humanas em geral, por meio de conceitos de integralidade e circularidade, ou seja, partes em interação, e do homem tratado não como um autômato ou robô reagente, mas como um sistema de personalidade ativa.

O paradigma funcionalista aplicado na análise de sistemas traz em si um conteúdo altamente conservador em termos de valores, concebendo o sujeito como simples detentor de status e desempenhador de papéis, em função da manutenção do sistema vigente.

A relação trabalho-tempo livre-turismo, na visão funcionalista sistêmica, não considera a ordem causal do tempo - a não ser no sentido da recuperação das forças - em que o tempo anterior determina o seguinte, não levando em conta que a alienação em um dos campos vem gerar atitudes de evasão ou compensação do outro. Apresenta-se aqui um metadiscurso impondo uma verdade injusta: a vida e os seus prazeres são reduzidos ao império da racionalização econômica. A compreensão do objeto turístico é una. O turismo passa a ser uma parte de um todo: o sistema econômico, tomado como subsistema produtivo. Essa abordagem diminui sua complexidade, ocasionando como objeto de conhecimento uma derivação simplificada como 'atividade' do campo produtivo. A falta de uma preocupação epistemológica por parte dos autores que estudam o turismo como sistema não os permitiu romper com a compartimentação analítica em seus estudos.

Como síntese desse limite epistemológico, em que o método sistêmico se sobrepôs ao objeto, estão as teses elaboradas a partir da Teoria Geral dos Sistemas quanto à metodologia de apreensão do objeto turístico pelos autores Alberto Sessa (1984), Pierre Lainé (1984), Sérgio Molina (2000), Martinez (2005), entre outros. Suas contribuições teóricas representam o momento préparadigmático na teoria do turismo.

O turismo será influenciado por certa ideia, partilhada por um dado conjunto cultural da diferença entre o sujeito (turista) que se desloca no tempo (nomadismo), que vai ao encontro de um determinado espaço e retorna ao local de origem (sedentarismo), essas categorias sociais e culturais estão na base da disciplina que se denomina turismologia; fazem parte de seu paradigma, pois são constituintes, formatadoras do seu objeto. 
Para a construção de uma disciplina científica, existe certo número de regras, princípios, estruturas mentais, instrumentos, normas culturais e/ou práticas, que organizam o mundo antes de seu estudo aprofundado.

O objeto de uma disciplina não existe, portanto antes da existência dessa própria disciplina; ele é construído por ela...uma disciplina científica não é definida pelo objeto que estuda, mas é ela que o determina... e na evolução de uma disciplina esse objeto pode variar. (Fouréz, 1995, p.106).

Os pesquisadores que utilizaram a Teoria Geral de Sistemas contribuíram para a estruturação de um método de abordagem do fenômeno turístico nas suas diferentes facetas. Permitiram assim operar distinções, que produziram novas classificações sobre o turismo, a ponto de servirem de base e de referência ao pensamento subsequente sobre ecossistema e turismo. Essas evidências são um efeito que sobrevém somente após o estabelecimento de uma disciplina científica.

\section{A APREENSÃO DO TURISMO COMO SISTEMA COMPLEXO}

O tratamento disciplinar que vem sendo dado ao estudo do turismo - e daí a dificuldade em sua compreensão como uma totalidade fenomênica - faz parte do contexto da produção do conhecimento científico moderno. Entende-se aqui totalidade fenomênica como a atualidade imediatamente dada à observação empírica efetiva, positivamente efetuada, manifestando-se numa constatação (Japiassu, 2002). A disciplinaridade é consequência do uso do paradigma analítico na construção dos saberes; até bem pouco tempo, este paradigma era tido como único e incontestável.

O método analítico divide problemas grandes ou complexos em partes, acreditando, assim, diminuir sua complexidade ao diminuir a intensidade das informações e das relações. O problema maior é dividido em questões menores; repartindo-o em partes independentes, para alcançar uma maior compreensão. Por quê? Para resolver problemas, nesta lógica, seria separar, solucionar os problemas de cada uma das partes ou setores e, assim, capacitar pelo conhecimento científico, ao enfrentamento a um problema maior. 
A tradição dos estudos monodisciplinares trouxe ao turismo um reducionismo na compreensão de sua episteme, como uma banalização em suas conceituações e consequentemente sua denominação ora como indústria, negócio, atividade, setor, entre outras, devido à falta de diálogo entre as disciplinas e a apropriação metodológica de cada campo disciplinar de forma interdisciplinar ao delinear seu objeto e método.

Concepções disciplinares restritas que não foram superadas nem mesmo com o modelo proposto por Jafar Jafari (1983), pois avançam em seu dispositivo cognitivo multidisciplinar, em que as formas de conhecimento do objeto em estudo advêm de áreas do conhecimento distintas (geografia, economia, administração, antropologia, etc.), essas, mesmo que dispostas em forma de uma teia, não são suficientes para romper suas fronteiras disciplinares metodológicas na compreensão do objeto do turismo. Mesmo que a multidisciplinaridade admita vasos comunicantes, conforme Figura 1, visando a uma compreensão mais holística, essa organização curricular não é suficiente para a construção de uma base teórico-metodológica própria à epistemologia do turismo. O exercício epistemológico aqui não se estabeleceu por completo, pois o objeto-turismo não foi reconstruído por suas categorias fundantes, e sim tomado como objeto dado, a coisa em si.

Os modelos sistêmicos, a partir da década de 1980, foram adotados em muitos estudos sobre o turismo, principalmente com a preocupação de estabelecer maior transferência de renda entre regiões, ou o chamado desenvolvimento regional pelo turismo. Alberto Sessa (1984) apresenta uma análise sistêmica cujo modelo é representado por elementos que são: o turista, que é definido por fluxo turístico; a indústria turística; os serviços turísticos; a oferta dos recursos; a infraestrutura e a superestrutura turística, entendida como sistema econômico turístico em relação ao sistema ecológico, educacional, sócio familiar, da ciência, da cultura.

A similaridade entre os autores que criaram seus modelos sistêmicos para o turismo se registra na aproximação quanto à definição dos elementos que compõem o sistema: a superestrutura, a demanda, os atrativos, a infraestrutura, os equipamentos e as instalações e, para poucos, como Sergio Molina, a comunidade local. 
Na trilha da construção teórico-metodológica, em 1998, sob o quadro teórico sistêmico, produziu-se um modelo interpretativo do turismo, cujas partes do objeto são estudadas profundamente em suas interações.

O problema do desenvolvimento do turismo é estudado em sistemas resultando em um modelo o Sistema de Turismo (SISTUR). Para solucionar um problema no subsistema ecológico, por exemplo, procura-se equacioná-lo nas suas muitas interações com os subsistemas econômico, social e cultural, demonstrando sua complexidade. Há uma preocupação em resolver problemas maiores, por meio do estudo das interações entre as partes. Mas construir uma teoria que dê conta das práticas turísticas deve ser uma conquista transdisciplinar, em que a cada momento é, simultaneamente, produzida e produtora, numa recursão organizacional, na qual a parte está no todo e o todo está na parte.

Ao desenvolver o SISTUR, Beni (1998) pretendeu retratar o turismo em toda sua multicausalidade até seu limite máximo, em um esquema sintetizador dinâmico que demonstrasse as combinações multifacetadas de forças e energias sempre em movimento. Assim foi adotada a conceituação de sistema, como o conjunto de procedimentos, doutrinas, ideias ou princípios logicamente ordenados e coesos, com intenção de descrever, explicar ou dirigir o funcionamento de um todo, de modo a produzir um modelo.

O modelo construído deveria ter a capacidade de retratar, até seus limites máximos, a configuração que tentava assumir um fenômeno como o do turismo, tão sujeito a variáveis interna e externa que escapavam, no momento de análise científica, a praticamente todo o esforço de cristalização para se poder estudálas, determiná-las e avaliá-las.

Como a energia desse sistema é vinda da relação entre oferta-demanda estabelecida pelo mercado, o fluxo de massa e de energia no interior do sistema processa-se através de "canais de comunicação" que, muitas vezes, não são claramente delineados. No transcorrer desse fluxo, pode ocorrer que parcelas de massa e de energia fiquem armazenadas em diversos setores, por lapsos de tempo das mais diversas escalas, constituindo reservas para o funcionamento do sistema. Dessa forma, no conjunto há quantidades de massa e de energia 
que estão constantemente circulando, transformando-se ou temporariamente retidas, conforme o modelo de Beni (1998), expressa na Figura 2.

Figura 2 - Modelo Sistêmico do Turismo- SISTUR

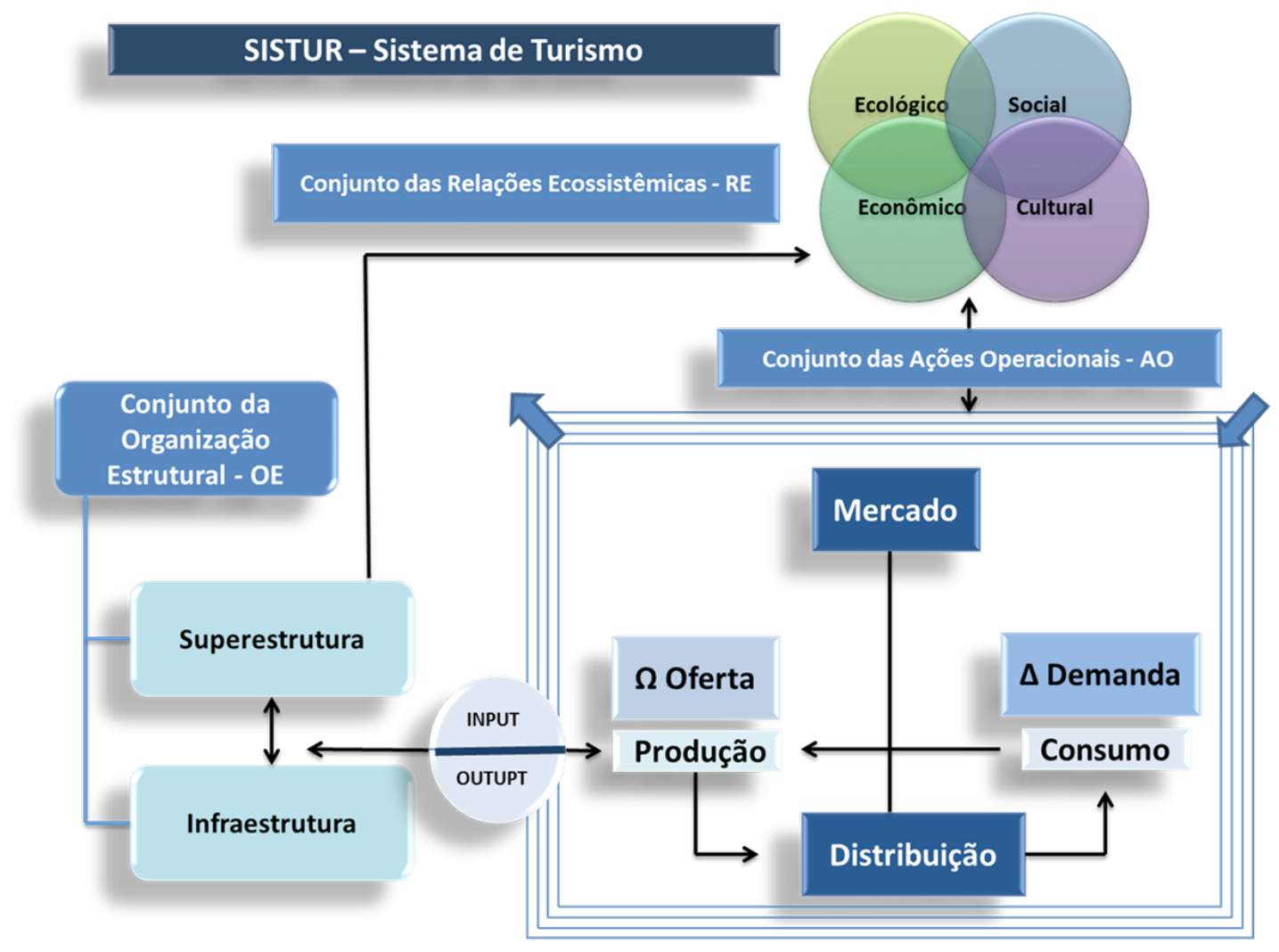

Fonte: Beni (1988).

O sistema turístico, assim entendido, é um sistema aberto, contrapondo-se à concepção histórica sobre sistemas fechados, utilizados pelos físicos e biólogos. Para os físicos, tudo iniciou muito certo, simplificado, em um mundo que caminha para a desordem (máxima entropia). Já para a Biologia, os organismos se formam organizadamente, dando a impressão que caminham rumo a uma crescente organização. Tanto na concepção física como na biologia dos sistemas abertos há necessidade de muita energia: eles interagem, eles consomem energia, até atingir certo equilíbrio, uma finalidade, uma complexidade estável.

Na visão sistêmica adotada no modelo do SISTUR desenhado, em 1998, as relações internas e externas a um sistema podem depender do sistema em si ou de seu ambiente. Se um sistema é submetido inevitavelmente a diversos determinismos de seu ambiente, esses determinismos terão sobre ele várias influências diferentes em função de suas capacidades próprias de reação. Essas capacidades do sistema introduzem as noções de regulação e de controle, 
que podem ser nulas ou, ao contrário, extremamente desenvolvidas. Convém também salientar a noção de hierarquia necessária nas estruturas e nas finalidades; sendo assim as unidades de regulação, de reação e de colocação devem estar em coerência.

Como todo modelo, o SISTUR foi se mostrando insuficiente para o objetivo proposto de se compreender o turismo em sua complexidade nos diferentes territórios e em suas diferentes formas de desenvolvimento. A exemplo da análise dos dados a partir das suas categorias, descrevendo como se configurava cada um dos subsistemas, objetivava-se com a soma das partes obter o diagnóstico do todo o sistema turístico, o que diante da concepção complexa do conhecimento (transdisciplinar) não foi possível, pois a simples soma das partes não revela a complexidade de suas conexões e a dinâmica das relações.

A prática científica não se reduz a uma sequência de operações, de procedimentos necessários e imutáveis, de protocolos codificados, o que faz da metodologia científica uma simples tecnologia. As "pesquisas" em turismo, assim apreendidas, frequentemente se convertem em estudos descritivos estatísticos preocupados em responder ao mercado (uma das facetas do fenômeno) sem compromisso com a realidade das comunidades onde atuam e seus ambiente socioculturais, colocando em segundo plano as concepções utilizadas, e de forma quase "desnecessária", ou protocolar, explicitam suas metodologias (entenda-se aqui por metodologias o conjunto de relações entre sujeito e objeto de conhecimento e de intervenção, admitindo-se a distinção entre o processo de produção de conhecimento e o processo da prática interventiva), raros são os estudos que apresentam noções operatórias ou categorias como forma de suas interpretações.

O estudo do turismo requer um questionamento sistemático de tudo que envolve o fazer-saber turístico, e do que se quer fazer; o saber turístico é e será objeto de desconstrução permanente. Esse pressuposto aponta uma virtude, tipicamente metodológica do conhecimento dialético, diante da análise da realidade turística, entendê-la como dinâmica, viva, orgânica, sempre em mutação. Construir uma teoria que dê conta das práticas turísticas deve ser uma conquista transdisciplinar, em que a cada momento é, simultaneamente, 
produzido o conhecimento e o produtor da ação desse conhecimento, numa recursão organizacional, na qual a parte está no todo e o todo está na parte.

\section{A TRANSDISCIPLINARIDADE COMO POSSIBILIDADE DE CONSTRUÇÃO DE UM OBJETO CIENTÍFICO: O TURISMO}

A interdisciplinaridade trata da síntese de duas ou várias disciplinas, instaurando um novo nível do discurso, caracterizado por uma nova linguagem descritiva e novas relações estruturais.

Entender o turismo como um campo de práticas histórico-sociais, que pressupõem o deslocamento do(s) sujeito(s), em tempos e espaços produzidos de forma objetiva, mas possibilitador de afastamentos simbólicos do cotidiano, coberto de subjetividades, e explicitador de uma estética diante da busca do prazer, é posicionar-se a partir de sua complexidade numa atitude interdisciplinar.

A reflexão epistemológica impõe aos próprios pesquisadores sobre os instrumentos de conhecimento dos quais as ciências dispõem, reflexão com vista a superar as crises revendo a pertinência dos conceitos, das teorias e dos métodos diante das problemáticas que são objeto de suas investigações. $\mathrm{Na}$ visão sistêmica complexa, em que o todo é mais que a soma das partes, isto é, no nível do todo organizado, há emergências em qualidades que não existem no nível das partes quando isoladas, o objeto da ciência se transforma: não é mais algo isolado, é um sistema complexo, pode ser uma das pegadas metodológicas a ser reconstruída.

Impõe-se o paradigma da interdisciplinaridade, esse nasceu da tomada de consciência cujas "lunetas" disciplinares (de cada disciplina social e humana) tornam-seimpotentes paraestudarproblemascadavezmaiscomplexos (Japiassu, 2002). Destina a criar um novo discurso que seria transcendente às disciplinas particulares, isto quer dizer, não é criar uma nova disciplina não científica, mas sim desenvolver práticas que podem ser negociadas entre diferentes pontos de vista ou interesses disciplinares sob um fenômeno ou objeto, propondo práticas políticas novas no campo de ação daquele conhecimento aplicado. 
A transdisciplinaridade partiu da crítica à fragmentação do saber em setores distintos e fechados, que são características de um enfoque particular real e de um sistema específico de relações dos seres humanos com seu entorno, ao contestar essa visão parcial que corresponde a uma visão racional de um mundo estável e estático, que foi imposta como última verdade da ciência moderna, impossível de explicar os problemas complexos e globais da humanidade: a ecologia, a energia. Essa concepção tendeu a abafar e a rechaçar outra espécie de enfoque devido ao sucesso tecnológico e econômico que reforçou a visão segundo a qual ciência seria uma abordagem mais verdadeira que aquela desenvolvida por outras culturas que enfatizam a inter-relação de tudo com tudo, ou outra cosmovisão.

Como essa atitude interdisciplinar, permite colocar o turismo como um fenômeno contemporâneo, de uma sociedade plugada em redes, convive com formas de uso do tempo liberado, das férias familiares/individuais - garantidas pelas leis trabalhistas aos cidadãos ainda empregados -, ao mochileiro, às novas experiências permitidas pela tecnologia, cujos deslocamentos no espaço e no tempo podem ser reais, mas também virtuais. A conjugação dos tempos vivenciais diferenciados, a espaços cada vez mais unos, favorecendo a convivência material entre os sujeitos e a vivência com intensidade das interrelações, em praias massificadas, destinos urbanos patrimonializados, ou em bucólicos recantos rurais, requer novas reflexões e teorias explicativas, para compreensão sistêmica orgânica nos processos de planejamento do turismo. As novas práticas turísticas requerem uma nova práxis turística.

Ao estudar o turismo como realidade humana, compreende-se como uma amálgama na qual tempo, espaço, diversão, economia, tecnologia, imaginário, comunicação, diversão, ideologia, hospitalidade, que são categorias fundantes de um fenômeno social contemporâneo, em que o protagonista é o sujeito, seja como produtor ou consumidor dessa prática social. Não é negada a contingência material do turismo em sua expressão econômica, mas ela ocorre historicamente, em espaços e tempos diferenciados, cultural e tecnologicamente construídos, a serem irrigados com o desejo de um sujeito biológico, nômade em sua essência. Sujeito objetivado, fundamental para a compreensão do 
fenômeno turístico como prática social, e subjetivado em ideologias, imaginários e necessidade de diversão e encontro, na busca do elo perdido entre prosa e poesia, conforme Figura 3 das categorias estruturantes do fenômeno turístico a seguir representado.

Figura 3: Categorias estruturantes do fenômeno turístico

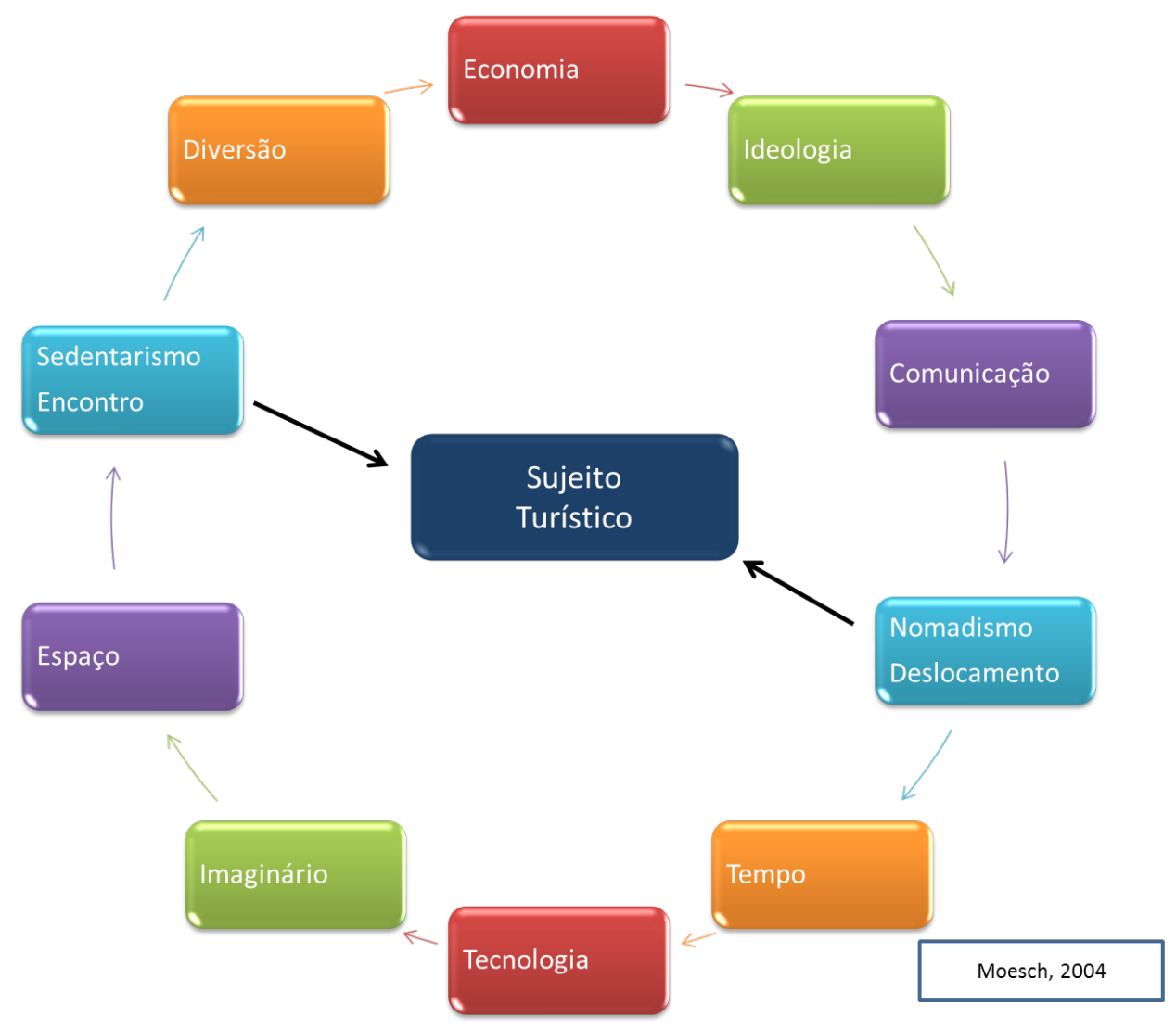

Fonte: Moesch (2004).

Ao partilhar as concepções de Morin (2001), quando define que interdisciplinaridade pode significar também a troca e a cooperação, faz com que possa vir ser alguma coisa orgânica. Na transdisciplinaridade trata-se, frequentemente, de esquemas cognitivos que podem atravessar as disciplinas, às vezes com tal virulência, que as deixam em transe. De fato, são os complexos de inter-multi-trans-disciplinaridade que realizam e desempenham um fecundo papel na história das ciências. Transdisciplinaridade, segundo Jantsch (1980), é o reconhecimento da interdependência de todos os aspectos da realidade, a consequência normal da síntese dialética provocada pela interdisciplinaridade, quando esta for bem-sucedida.

A inter e a transdisciplinaridade fazem emergir da confrontação das disciplinas dados novos que as articulam entre si, oferecendo uma nova visão 
da natureza e da realidade. Ela não procura o domínio sobre as disciplinas, mas o caminho de abertura de todas elas àquilo que as atravessa e as ultrapassa. É preciso viver efetivamente a experiência do transmitir e aprender em união total, em que a herança acumulada do passado é reinterpretada e visualizada apenas no que permanece de universal e para todos, que se erigiu a partir do princípio dialógico-hologramático de Morin (2001), a reconstrução do sistema turístico, cuja dinâmica da realidade impôs uma revisão de seu conjunto de sistemas e subsistemas como partes de um todo, de um "modelo explicativo", em um totalidade/parte do todo, representado pela Figura 4 como objetos de um "eixo epistemológico complexo".

Figura 4: Modelo Sistêmico Complexo do Turismo

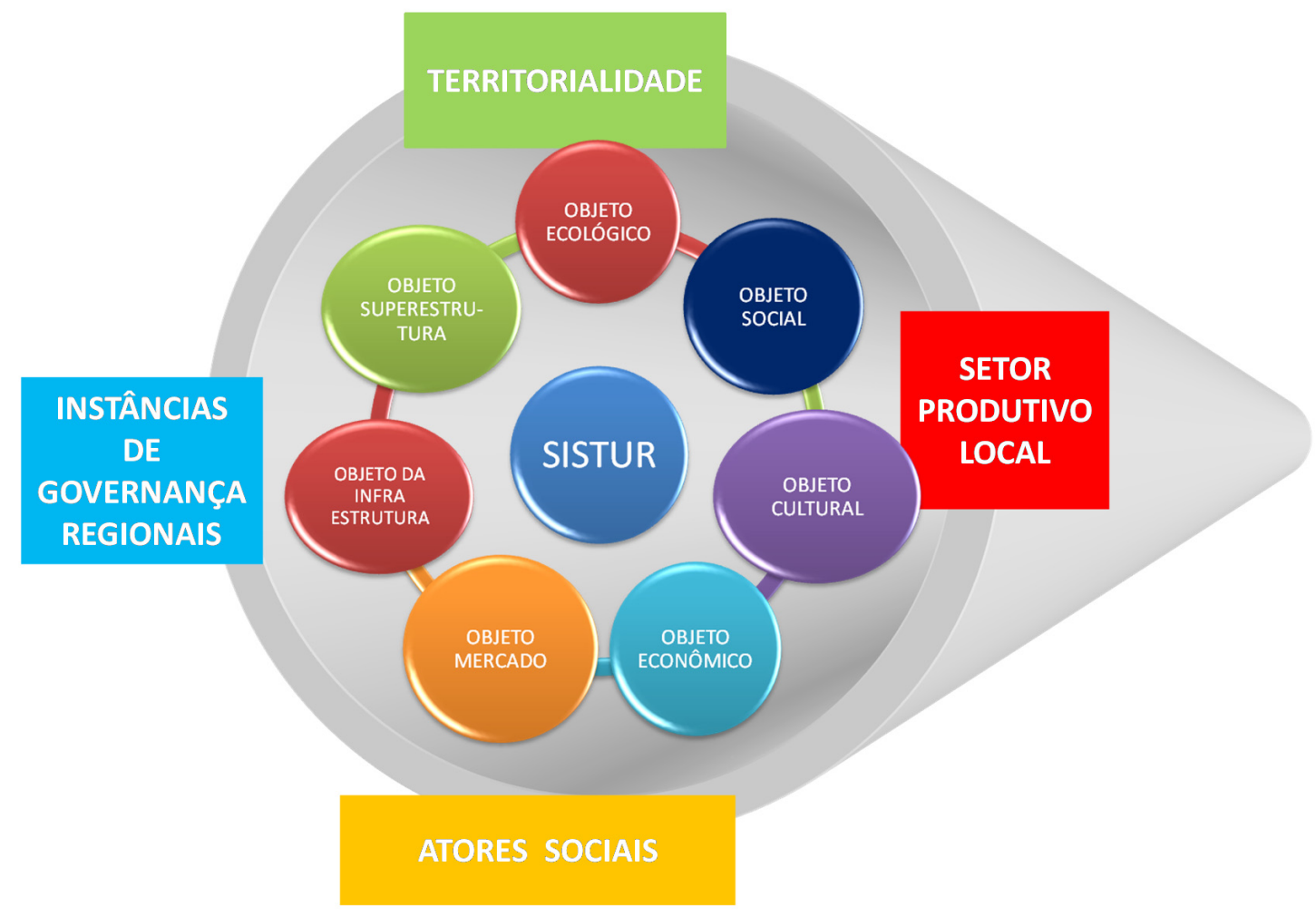

Fonte: Beni (2014).

O SISTUR, reconstruído a partir da teoria da complexidade, representa sair do modelo explicativo da ciência rigorosa, ou eixo ou modelo da Biologia, e passar a reconstruir o turismo por um modelo histórico-cultural, aceitando a questão global da existência do fenômeno e abrindo-se a uma pesquisa e a um debate em uma linguagem elaborada, iniciando uma busca de sentido, o que vem a ser estruturante no fenômeno turístico. Ou seja, seus objetos constituintes 
do todo: objeto da infraestrutura, objeto superestrutura, objeto social, objeto cultural, objeto ecológico, objeto econômico e objeto do mercado.

A reconstrução do modelo do SISTUR pela teoria da complexidade, proposta nesse artigo, apreende como sistema vivo, que se auto-organiza e realiza sua autoprodução, ao mesmo tempo em que realiza a auto-eco-organização (o sistema é, simultaneamente, totalidade/parte, uma unidade global que é parte de outra unidade, tudo está interconectado com tudo, homem e natureza), e a sua auto-ecoprodução (só é possível o ser, a existência e a vida em um sistema-organização), pois ele está envolvido em um ambiente externo que se encontra, ele mesmo, integrado a um sistema eco-organizador, o ecossistema. Conforme o princípio da auto-eco-organização tem valor hologramático, assim como a qualidade da imagem hologramática (Figura 5), está ligada ao fato de que cada ponto possui a quase totalidade de informação do todo, do mesmo modo, de certa maneira o todo é o todo que nós somos parte, está presente em nosso espírito (Morin, 2001).

Figura 5: Modelo Ecossistêmico do Turismo

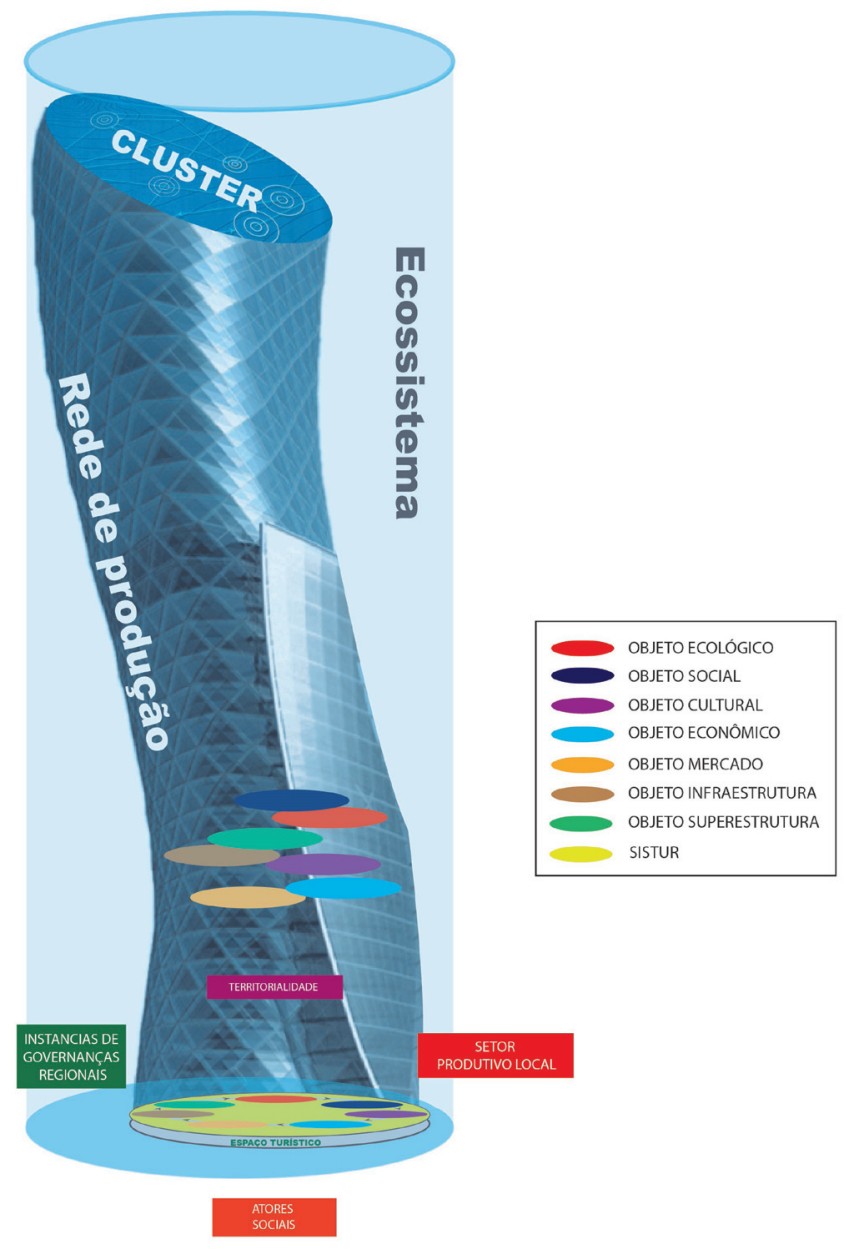

Fonte: Beni e Moesch (2015). 
Uma primeira via de acesso é fornecida pelas "três teorias" que constituem a teoria da complexidade - a da informação, da cibernética (ciência dos sistemas da comunicação e controle) e dos sistemas. Essas três teorias, aparentadas e inseparáveis, surgiram no início dos anos 40 e com grande intensidade se enriqueceram mutuamente. A teoria da informação permite entrar em um universo no qual ao mesmo tempo existem ordem (redundância) e desordem (ruído) - e desse universo se extrai algo novo, ou seja, a informação em si, que se torna então organizadora (programadora) de uma máquina cibernética. A informação que indica, por exemplo, o vencedor de uma batalha, dissipa uma incerteza, a que anuncia a morte súbita de um tirano traz o inesperado e, ao mesmo, tempo, a novidade.

Em sua teoria dos autômatos auto-organizadores, Von Neumann (apud Morin, 2000) questiona a diferença entre as máquinas artificiais e as "máquinas viventes". E assinala esse paradoxo: os elementos das máquinas artificiais são muito bem fabricados, super afeiçoados, mas se degradam desde que a máquina começa a funcionar. Por outro lado, as máquinas viventes são compostas de elementos pouquíssimos confiáveis, como as proteínas, que se degradam sem cessar; mas essas máquinas possuem a estranha propriedade de se desenvolver, de se reproduzir, de se autorregenerar, substituindo por novas as moléculas degradadas e as células mortas.

De outra forma, Prigogine (apud Morin, 2003) introduziu a ideia de organização a partir da desordem. No exemplo dos turbilhões de Bernard, pode-se observar como estruturas coerentes se constituem e se auto mantêm, a partir de certo limiar de agitação e abaixo de outro limiar. Para se manter, essas organizações necessitam alimentar-se de energia, consumi-la e "dissipá-la". No caso do ser vivo, este tem suficiente autonomia para extrair energia de seu meio ambiente, e inclusive dele colher informações e absorver sua organização, processo que Morin (2003) denominou auto-eco-organização.

Portanto, o método da teoria da complexidade de Morin (2003) se apresenta como um edifício de vários andares. A base é formada a partir das três teorias (informação, cibernética e sistemas) e contém elementos necessários para uma teoria da organização. Em seguida vem o segundo andar, com as ideias de 
Neumann (1996), Foerster (1957), Atlan (1992) e Prigogine (1996) sobre a autoorganização. A esse edifício ele acrescentou elementos suplementares, como os três princípios: o dialógico, o da recursão e o hologramático.

O princípio dialógico une dois princípios ou noções antagônicas, que aparentemente deveriam repelir uma à outra, mas que são indissociáveis e imprescindíveis para compreender uma mesma realidade. Pascal afirmava: "O contrário de uma verdade não é o erro, mas uma verdade contrária."

O princípio da recursão organizacional vai além do princípio da retroação (feedback), ultrapassa a noção de regulação pela autoprodução e da autoorganização. É uma curva geradora na qual os produtos e os efeitos são eles próprios produtores e causadores daquilo que produz. Assim nós, indivíduos, somos produtos de um sistema de reprodução que retoma ao fundo dos tempos, mas esse sistema só pode se reproduzir se nós mesmos nos tornarmos seus produtores nos acasalando. Os indivíduos humanos produzem a sociedade em e por suas interações, mas a sociedade, como um todo emergente, produz a humanidade desses indivíduos ao proporcionar-lhes a linguagem e a cultura.

Como se vê, o pensamento complexo de forma alguma é um pensamento que exclui a certeza para inserir a incerteza, que exclui a separação para inserir a inseparabilidade, que exclui a lógica para autorizar todas as transgressões. $O$ processo consiste, pelo contrário, numa incessante ida e volta entre certezas e incertezas, entre o elementar e o global, entre o separável e o inseparável. Não se trata de abandonar os princípios da ciência clássica - ordem, separabilidade e lógica -, mas de integrá-los em um esquema ao mesmo tempo mais amplo e mais rico. Não se trata de opor um holismo global e vazio a um reducionismo sistemático; trata-se de vincular o concreto das partes à totalidade. É preciso articular os princípios de ordem e desordem, separação e junção, autonomia e dependência, que são ao mesmo tempo complementares, competidores e antagônicos ao seio do universo.

O pensamento complexo é, essencialmente, o pensamento que integra a incerteza e que é capaz de conceber a organização. Que é capaz de unir, contextualizar, globalizar, mas ao mesmo tempo reconhecer o singular e o concreto. 
A epistemologia do turismo proposta tem significação apenas para aqueles a quem a história e as decisões humanas colocam uma questão sem querer impor esta questão a todos, sem absolutizar um novo discurso, dominando os anteriores.

O objeto de estudo do turismo é um objeto em construção, não é um objeto construído, pois o fenômeno turístico é um acontecimento dinâmico, pois tem como motor as práticas sociais em seu tempo sócio-histórico.

Todo o progresso importante do conhecimento, como assinala Kuhn (1970), se opera necessariamente pela quebra e pela ruptura de sistemas fechados, que não possuem dentro deles a mesma atitude de transcendência que o próprio fenômeno carrega. Quando uma teoria se mostra incapaz de integrar observações cada vez mais centrais, quebrando o próprio sistema que lhe deu sua coerência com seu fechamento, é substituído, por vezes, relativizando os princípios anteriormente aceitos, o que se denomina de quebra de paradigmas.

A razão da não construção de uma Ciência do Turismo está na má compreensão do domínio do objeto turístico, objeto de investigação mal definido e consequente assimilação insuficiente dos conhecimentos adquiridos.

A amplitude do objeto desafia o entendimento humano simplificador; esse objeto que, simultaneamente, é exterior a nós. Está em nós e interage conosco, suporta mal o isolamento do sujeito em relação ao seu objeto, o que leva à busca de um método transdisciplinar para a compreensão do objeto do turismo.

\section{A TEORIA DA COMPLEXIDADE E O ECOSSISTEMA TURÍSTICO}

Construir um novo campo teórico para o turismo requer um método que avance na concepção do que seria conhecimento, ciência e teoria. O tratamento disciplinar que vem sendo dado ao estudo do turismo $\square$ e daí a dificuldade em sua superação como setor econômico e/ou atividade mercadológica $\square$ faz parte do contexto da produção do conhecimento científico contemporâneo, que desvela as relações ecossociais dos sistemas complexos. 
Compreender a problemática do desenvolvimento crescente do turismo é relevante não só à medida que seus produtores, vendedores intermediários, consumidores, continuam produzindo, vendendo e consumindo sem limites ou critérios, sem outro fim que o próprio benefício do primeiro e a satisfação egoísta do consumidor, mas pela persistência do problema, disfarçado nas concepções implícitas destes conceitos.

Essa postura, emergente de uma cultura de mercado capitalística, desconhece a essência do fenômeno turístico, o qual exerce uma pressão crescente sobre a produção da subjetividade social, o ecossistema, o modo estético, a herança cultural, existentes nas localidades visitadas, gerando agenciamentos possíveis de ressignificação junto à realidade, através da relação entre visitantes e visitados.

Turismo é processo humano, ultrapassa o entendimento como função de um sistema econômico. Como um processo singular, necessita de ressignificação às relações impositivas, aos códigos capitalísticos e aos valores colocados como bens culturais. Ainda, considerando o imbricamento ou a sobreposição de sistemas, bem como a visualização hologramática, percebem-se trocas energéticas, materiais e informacionais que ocorrem entre o sistema e o ambiente, permitindo que ele internalize tudo o que necessita para que possa manter sua organização e estrutura em funcionamento.

A complexidade, para Morin (2001), constituiria, assim, o tecido, o pano de fundo, a trama, as interações que, por acaso, ocorrem. Se no tecido é onde ocorrem os acontecimentos, pode-se então considerar que a complexidade é um fator constitutivo da vida correspondente a esse entrelaçamento de fenômenos e processos que constituem a sua dinâmica natural em diferentes níveis de ascenso e descenso.

O princípio do círculo recursivo ultrapassa a noção de regulagem para a de autoprodução e de autorregulação. Os produtos e os efeitos são eles próprios, vistos como os produtores e os causadores daquilo que os produz. $\mathrm{Na}$ construção dos modelos de apreensão do fenômeno turístico de forma sistêmica, explicita-se a necessidade da existência de uma estrutura, como um feixe de relações entre elementos que o compõem. Esses elementos são 
complementares na sua distribuição, o todo em que se constituem é cabal e suficiente, há uma forte inter-relação entre as partes. É uma estrutura de partes satisfatoriamente distribuídas, que se associam e complementam. Toda a estrutura pressupõe um sistema, pelo menos implícito e realizável, sendo sua condição prévia e necessária para ele existir. De um lado, há o contorno geral do todo; de outro, a possibilidade de redução da complexidade do todo em nível explicativo da estrutura, que repetiria dentro de si o retrato em miniatura do todo, dando, ao mesmo tempo, a razão por que o todo se mantém.

O turismo é um sistema aberto, orgânico, que não pode ser estudado como uma entidade radicalmente isolada. Daí seu conteúdo interdisciplinar e transdisciplinar. Teórica e empiricamente o conceito de sistema aberto complexo abre a porta a uma teoria da evolução, que não pode derivar mais que de interações entre sistema e ecossistema e que, em seus laços mais notáveis, pode ser concebido como um transbordo do sistema em um metassistema, ou ecossistema turístico, e aqui se estabelece o desafio da trilha.

Finalmente, sendo a relação fundamental entre os sistemas abertos e o ecossistema de ordem material energético e organizacional/informacional, poder-se-ia tratar de compreender o caráter ao mesmo tempo determinado e aleatório da relação ecossistêmica. Seu objeto no formato de sua complexidade desafia uma epistemologia social para o entendimento de sua gênese. Assim, as categorias como tempo, espaço, tecnologia, economia, comunicação, ideologia, imaginário, hospitalidade, diversão, entre outras, constituem-se na sua práxis. Práxis turística não disjuntiva, nem linear, mas sim uma construção dinâmica, permanente, na qual o sujeito turístico em sua transumância se move, constrói de forma imaginal, comunica seus desejos mais íntimos, em processos objetivos de fluxos (deslocamento/viagem/transportes), de fixos (estada, hospedagem, alimentação, acolhimento e segurança) e de prazer (o encontro cultural, a diversão), que só se estabelece se houver o encontro possibilitado pela hospitalidade.

Relações sociais que configuram a esse ecossistema turístico sua energia, sua força dinamizadora como humana. O sujeito turístico é que permite a existência deste sistema e não o inverso. Essa mesma energia que mantém a dinâmica do sistema turístico é produtora de necessidades objetivas, que de forma espiralada geram uma reprodução ampliada de processos econômicos e culturais, que 
atendem ao desejo de transumância e permanência transitória do sujeito turístico, em seu movimento de ir-vir, seu fluxo nômade.

Tendo como paradigma a complexidade, a análise de sistemas constrói modelos que buscam explicar o fenômeno turístico na sua totalidade, transpondo suas preocupações com a eficácia dos planos turísticos e o papel do estado no controle normativo desse desenvolvimento. A ideia de que os efeitos podem ser auto-eco-reguladores de suas supostas causas dentro de um sistema complexo e de que os observadores podem modificar, pela via interativa o que estão a observar, criou novo marco epistemológico para apreender o fenômeno turístico como um campo científico, cujo objeto transdisciplinar compõe-se da integralidade e da circularidade presente no ecossistema turístico construído.

A teorização aqui proposta não toma para si um metadiscurso totalizante do que vem a ser um objeto transdisciplinar como o turismo. Adota uma postura epistemológica aberta a novas reflexões, diálogos, incertezas, cruzamentos e amálgamas teóricas, dentre elas como discorrer a partir de modelos sistêmicos com os princípios da Teoria da Complexidade, já que esta não busca a síntese de uma certeza provável, e sim o processo de organização-desorganização permanente dos fenômenos? Fica aberto o desafio para a consolidação de uma epistemologia do turismo.

\section{REFERÊNCIAS}

Bacon, F. (1999). Indicações Acerca da Interpretação da Natureza.São Paulo: Nova Cultura.

Bertalanffy, L. (1976). Teoría General de los Sistema. México: FCE

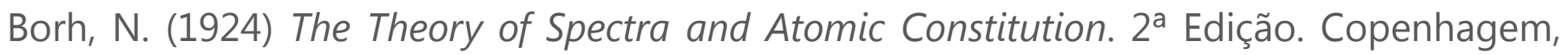
Dinamarca.

Bruyne, P.; Herman, J.; Schoutheete, M. (1977). Dinâmica da Pesquisa em Ciências Sociais. Rio de Janeiro: Francisco Alves.

Bunge, M. (2000). La Investigacion Científica. Barcelona: Colección Convivium: Ariel.

D’Ambrosio, U. (1997). Transdisciplinaridade. São Paulo: Palas Athenas. 
Fouréz, G. (2002). A Construção das Ciências. As Lógicas das Invenções Científicas. Lisboa. Instituto Piaget, 2002.

Japiassu, H. (2002). Introdução as Ciências Humanas. São Paulo: Letras \& Letras. Jafari, J. (1983). Anatomy of the Travel Industry. In.: Cornelll Hotel ans Restaurant Administration Quarterly, Vol. 24, Nº1, May. - p.77.

Kunh, T. (1970). A Estrutura das Revoluções Científicas. São Paulo: Ed.Perspectivas.

Lainé, P. (1985) Utilisation de La Théorie des Systems pour l'amenagement Touristique. In.: SESSA, A. La Scienza dei Sistemi per lo Sviluppo del Turismo. Roma: Agnesotti, 1985, p-185-194

Leiper, N. (1979) The Framework of Tourism: Towards a Definition os Tourism, Turist, and the Tourist Industry. In: Annals of Tourism Research. Great Britain: Pergamon, v.6, p.390-407

Lukács, G. (1978). As Bases Ontológicas do Pensamento e da Atividade do Homem. In.: Revista Temas de Ciências Sociais. São Paulo: Editora Ciências Humanas.

Martinez, A. de J.J. (2005). Aproximação à Conceituação o Turismo a partir da Teoria Geral dos Sistemas. In: Trigo, L.G.G.; Panosso Neto, A.; Carvalho, M.A.; (Eds). Análises Regionais e Globais do Turismo Brasileiro. São Paulo: Roca, 2005. P. 109-148

Moesch, M. (2000). A Produção do Saber Turístico. $2^{\mathrm{a}}$ Edição. São Paulo: Editora Aleph.

Moesch, M. (2004). Epistemologia Social do Turismo. In.: Dissertação de Doutorado. ECA/ USP. São Paulo.

Molina, S. (2000). Conceptualización Del Turismo. México: Limusa.

Morin, E. (2001a). Ciência com Consciência. $4^{a}$ Edição, Rio de Janeiro: Bertrand Brasil.

Morin, E. (2003). O Método I: a natureza da natureza. Porto Alegre: Sulina.

Morin, E. (2001b). Introdución Al Pensamiento Complejo. Espanha,Barcelona: Gedisa Editorial.

Nicoloescu, B. et al. (2000). Educação e Transdisciplinaridade. Brasília: UNESCO.

Noschang, J. (2014). O modelo teórico SISTUR diante da complexidade do fenômeno turístico. In.: Dissertação de Mestrado. UNB/Mestrado em Turismo.

Sessa, A. (1984). La Scienza dei Sistemi per lo Sviluppo del Turismo. Roma: Agnesotti.

Smuts, J. C. (1996). Holism and Evolution. New York: The Gestalt Journal Press.

Talcott, P. (1974). Sistemas das Sociedades Modernas. São Paulo: Juponeira. 
Weil,P. (1993). Rumo à Nova Transdisciplinaridade: Sistemas Abertos de Conhecimento. São Paulo: Summus.

Wiener, N. (1989). The Human use of Human Beings Cybernetics and Society. $5^{a}$ Edição, London: Free Association Books 26.

\section{CONTRIBUIÇÃO DOS AUTORES NA CONSTRUÇÃO DO ARTIGO}

BENI: Bases e inovações do SISTUR - Sistema de Turismo, integrado com a parte epistemológica

MOESCH: Construção do texto, com discussão teórica e metodológica 